\title{
PERMANÊNCIA NA EDUCAÇÃO EM TEMPOS DE PANDEMIA: REFLEXÕES A PARTIR DA LICENCIATURA EM LETRAS DO IFF
}

\section{PERMANENCE IN EDUCATION IN TIMES OF PANDEMIC: REFLECTIONS BASED ON THE DEGREE IN LETTERS DO IFF}

\section{PERMANENCIA EN LA EDUCACIÓN EN TIEMPOS DE PANDEMIA: REFLEXIONES BASADAS EN LA LICENCIATURA EN LETRAS DO IFF}

Jonis Manhães Sales Felippe ${ }^{1}$

\begin{abstract}
Resumo: O presente trabalho analisou os resultados de uma pesquisa quantitativa realizada com estudantes de um curso de licenciatura, em uma instituição pública federal, acerca das suas condições de permanência na educação superior durante a crise sanitária e social vivida no Brasil no ano de 2020. Os dados produzidos foram organizados em gráficos e tabelas e discutidos à luz das legislações e regulamentações recentes no país, do debate teórico sobre desigualdades sociais e educacionais e do perfil nacional dos estudantes da mesma área de formação produzido pelo INEP, além de dados sobre o perfil do próprio curso antes da pandemia. As conclusões apontam para um processo de degradação das condições de reprodução material dos estudantes e de suas famílias, o que fragiliza a própria ideia de permanência e aponta para o risco de aprofundamento das desigualdades educacionais em uma situação de aulas regulares por meios digitais, conforme possibilidade aberta pelo MEC.
\end{abstract}

Palavras-chave: Permanência na educação. Ensino superior. Licenciatura.

Abstract: This work analyzed the results of a quantitative research carried out with students of an undergraduation course, in a federal public institution, about their conditions of permanence in higher education during the health and social crisis experienced in Brazil in 2020. The data produced were organized in graphs and tables and discussed in the light of recent laws and regulations in the country, of the theoretical discussion on social and educational inequalities and the national profile of students in the same training area produced by INEP, in addition to data on the profile of the course before the pandemic. The conclusions point to a process of degradation of the material reproduction conditions of students and their families, which weakens the very idea of permanence and points to the risk of deepening educational inequalities in a situation of regular classes by digital means, under possibility opened by MEC.

Keywords: Permanence in education. Higher education. Teacher education.

\footnotetext{
${ }^{1}$ Instituto Federal Fluminense (IFF). Campos dos Goytacazes, Rio de Janeiro, Brasil.
} 
Resumen: El presente trabajo analizó los resultados de una investigación cuantitativa llevada con estudiantes de un curso de licenciatura, en una institución pública federal, sobre sus condiciones de permanencia en la educación superior durante la crisis de salud y social experimentada en Brasil en 2020. Los datos producidos fueron organizados en gráficos y tablas y discutidos a la luz de las recientes leyes y reglamentos en el país, del debate teórico sobre las desigualdades sociales y educativas y del perfil nacional de los estudiantes de la misma área de capacitación producida por el INEP, además de los datos sobre el perfil del propio curso antes de la pandemia. Las conclusiones indican un proceso de degradación de las condiciones de reproducción material de los estudiantes y de sus familias, lo que debilita la idea de permanencia y señala el riesgo de profundizar las desigualdades educativas en una situación de clases regulares por medios digitales, como fue permitido por el MEC.

Palabras clave: Permanencia en educación. Educación superior. Licenciatura.

\section{INTRODUÇÃO}

Os Institutos Federais de Educação, Ciência e Tecnologia foram criados em 2008 e caracterizados como instituições de ensino superior, básico e profissional, com estrutura pluricurricular e multicampi, tendo como um dos seus objetivos ministrar cursos superiores "de licenciatura, bem como programas especiais de formação pedagógica, com vistas na formação de professores para a educação básica, sobretudo nas áreas de ciências e matemática, e para a educação profissional" (BRASIL, 2008, p.3). Para garantir que tal objetivo se cumpra, a lei ainda prevê que 20\% das vagas de cada um desses Institutos deverão ser direcionadas para tais cursos.

Como se sabe, a formação de professores ainda é um dos grandes desafios nacionais, tanto pelas condições de trabalho, muitas vezes aviltantes, quanto pelo baixo prestígio da profissão no Brasil, que levam ao desinteresse dos jovens pela docência (ARANHA e SOUZA, 2013). Somado a isso, tem-se o fato de que muitos professores em atuação no Brasil ainda não possuem formação em licenciatura na área em que lecionam, fator que fundamentou a criação da meta 15 no Plano Nacional de Educação (2014-2024), que atribui ao Estado brasileiro a responsabilidade de:

Garantir, em regime de colaboração entre a União, os Estados, o Distrito Federal e os Municípios, no prazo de 1 (um) ano de vigência deste PNE, política nacional de formação dos profissionais da educação de que tratam os incisos I, II e III do caput do art. 61 da Lei n 9.394, de 20 de dezembro de 1996, assegurado que todos os professores e as professoras da educação básica possuam formação específica de nível superior, obtida em curso de licenciatura na área de conhecimento em que atuam (BRASIL, 2014, p. 12). 
Dessa maneira, o Instituto Federal Fluminense, ao ofertar diversos cursos de licenciatura ${ }^{2}$ nas regiões Norte, Noroeste e Lagos do Estado do Rio de Janeiro, vem dando uma importante contribuição para a formação de novos profissionais e a qualificação de profissionais já atuantes, sobretudo na Educação Básica. O curso de Licenciatura em Letras - Português e Literaturas não foge a tal missão, tendo como objetivo geral do seu PPC "formar professores para atuar na Educação Básica e Educação Profissional, comprometidos com princípios éticos formadores de uma cidadania reflexiva e crítica" (IFF, 2019, p. 35).

Como demonstram as recentes avaliações de reconhecimento e os resultados do ENADE (Exame Nacional de Desempenho de Estudantes) que atribuíram nota máxima (5) ao curso, a Licenciatura em Letras - Português e Literaturas do IFF não apenas oferta a formação adequada em nível de graduação para o público citado, como o faz com excelência. Justamente para manter esse nível de qualidade é que vem sendo desenvolvido, desde o ano de 2019, o projeto de pesquisa "Ingresso e permanência no curso de Licenciatura em Letras do IFF campus Campos Centro: um estudo sobre o perfil, as condições materiais e os projetos de vida dos estudantes", vinculado ao Núcleo de Estudos Avançados em Educação (NESAE) e com apoio do Conselho Nacional de Desenvolvimento Científico e Tecnológico (CNPQ).

O referido projeto apresenta-se como uma iniciativa que pretende aprofundar os conhecimentos acerca dos estudantes que procuram e permanecem no curso de Licenciatura em Letras - Português e Literaturas, apesar dos desafios nacionais relativos à formação de professores já citados e das barreiras sociais e pessoais que, muitas vezes, levam os alunos a abandonar o ensino superior (MELLO, 2007; LAHIRE, 2008). Em um contexto de pandemia e de crise sanitária como o que vivemos atualmente, tais barreiras sociais podem ganhar dimensões ainda mais graves e determinantes para a permanência ou o abandono de um curso de graduação.

Dessa maneira, o presente artigo busca oferecer reflexões sobre a realidade dos alunos nesse período e sobre as consequências das escolhas políticas que podem ser feitas pelos cursos e pelas instituições de ensino superior, tomando o caso concreto de um curso de graduação da rede pública federal. Embora trate de uma situação particular, a finalidade maior desse trabalho não é oferecer uma resposta conclusiva acerca dos caminhos que todas as instituições de ensino superior

\footnotetext{
${ }^{2} \mathrm{O}$ Instituto Federal Fluminense oferece atualmente cursos de licenciatura em 5 dos seus campi, espalhados pelo interior do Rio de Janeiro (dois deles no município de Campos dos Goytacazes, campus Centro e campus Guarus, além dos municípios de Cabo Frio, Itaperuna e, mais recentemente, Macaé). Os cursos, todos presenciais, oferecem formação nas áreas de Ciências da Natureza (química, física ou biologia), Educação física, Geografia, História, Letras - Português e Literaturas, Matemática, Música e Teatro.
} 
devem tomar no contexto de crise, mas sim abrir possibilidades de análises que apontem para a importância de se pensar a permanência dos estudantes a partir das suas condições objetivas de vida. Isso ganha especial destaque nos cursos cujo perfil dos alunos já é marcado por recortes de classe, como é o caso das licenciaturas no Brasil.

Para alcançar tal objetivo, foi desenvolvida uma pesquisa de caráter quantitativo a partir da aplicação de um questionário sobre as condições de permanência dos alunos em tempos de pandemia e da análise de dados sobre o perfil dos estudantes da área, tanto nacionalmente quanto na própria instituição. Essas informações são discutidas a luz de pesquisas e trabalhos recentes sobre os temas da desigualdade social e educacional e da permanência dos estudantes no ensino superior no Brasil.

\section{A REALIDADE SOCIAL DOS ESTUDANTES DA LICENCIATURA EM LETRAS - PORTUGUÊS E LITERATURAS DO IFF: REFLEXÕES EM TEMPOS DE PANDEMIA}

O curso de Licenciatura em Letras - Português e Literaturas aqui discutido possuía, no momento da pesquisa, cerca de 230 estudantes devidamente matriculados e inscritos em disciplinas no semestre referente ao período de 2020.1. Na aplicação do questionário entre os dias 30/04/20 e $07 / 05 / 20$, foram registradas 199 respostas, o que corresponde a cerca de $87 \%$ dos matriculados e inscritos em disciplinas. Os estudantes responderam por livre iniciativa e foram informados sobre o anonimato das informações em toda a utilização e divulgação dos dados.

O questionário foi aplicado por meio da internet e por ligação telefônica, nos casos em que o aluno informava não ter acesso para responder online. Os dados produzidos estão sendo utilizados pela coordenação do curso para discussão sobre as estratégias de ensino possíveis nesse período de pandemia e para a identificação dos alunos em situação de maior fragilidade social e financeira. A partir dessas informações, foram feitos encaminhamentos à equipe de assistência estudantil do campus.

As perguntas do questionário centraram-se em dois eixos: situação socioeconômica e acesso a recursos tecnológicos necessários a implementação de estratégias de ensino remoto. Cabe ressaltar que a Portaria MEC no 343 de 17 de março de 2020 já havia autorizado a substituição, no ensino superior, de aulas presenciais por aulas em meios digitais por 30 dias, o que acabou sendo renovado em 12 de maio pela Portaria MEC no 473 do mesmo ano. No momento de elaboração deste artigo, está em vigor a Portaria MEC no 544 de 16 de junho de 2020, que prorroga a possibilidade de substituição das aulas presenciais até 31 de dezembro de 2020. Esses mesmos 
documentos permitem que as instituições de ensino superior optem pela suspensão das atividades acadêmicas pelo mesmo período.

Considerando as possibilidades em questão, qual seria a alternativa mais viável para os estudantes de ensino superior brasileiros, especialmente os matriculados em instituições públicas? De que forma essas escolhas podem resguardar o direito ao acesso à educação sem produzir ainda mais desigualdades entre os alunos ou sem promover um processo de desvinculação com o curso, o que pode deflagar em evasão? Como já salientado, este trabalho não possui a pretensão de oferecer respostas prontas para essas questões tão complexas, mas subsídios para que, a partir da experiência e da realidade do curso em análise, outras instituições possam realizar suas investigações e produzir suas reflexões e estratégias. O que se sabe ao certo é que a realidade de cada instituição e de cada curso é particular, exigindo respostas pensadas especificamente a partir do cenário factual dos seus alunos.

Apesar disso, como a abordagem adotada nesta pesquisa não visualiza possibilidades de se compreender o cenário local deslocado da realidade mais ampla, as pesquisas e os dados nacionais sobre o perfil dos estudantes de licenciatura e as condições de permanência no ensino superior no Brasil são elementos fundamentais para a interpretação das informações levantadas.

No caso do curso de Licenciatura em Letras - Português e Literaturas do IFF, o perfil dos alunos é preponderantemente marcado por recortes de gênero, geração e de origem escolar. Conforme dados extraídos do sistema acadêmico da instituição no momento da pesquisa, 82\% dos estudantes são do sexo feminino e $72 \%$ possuem até 24 anos de idade. Em relação à origem escolar, $83 \%$ cursaram o ensino médio em escola pública e $17 \%$ em escola privada. Quanto à identificação de raça/cor, $55 \%$ se autodeclaram brancos, $41 \%$ pretos ou pardos e $4 \%$ outras etnias ou não responderam.

Esses dados vão ao encontro das pesquisas de Gatti (2010), que apontam a feminização da docência como uma marca existente desde as escolas normais no final do século XIX no Brasil. Também os dados do ENADE de 2017, aplicado aos alunos do ensino superior por área de formação, confirma o reflexo das características nacionais no cenário local. Segundo o relatório produzido pelo INEP (2017) referente à área de Letras-Português (licenciatura presencial), as pessoas do sexo feminino correspondiam a 77,9\% dos alunos. A faixa etária mais recorrente foi também a de até 24 anos $(36,7 \%)$, enquanto a identificação de raça/cor correspondia a: 60,6\% de pretos ou pardos; $32,9 \%$ de brancos; $6,4 \%$ de outras raças ou não responderam. Nas instituições públicas, o percentual de estudantes oriundos de escolas também públicas no ensino médio (integralmente) foi de 80,5\%. 
Pelas informações acima, percebe-se que o curso de Letras - Português e Literaturas do IFF, mantém as características gerais nacionais, em termos percentuais, no que se refere aos elementos básicos de perfil como gênero e origem escolar. Já em relação à idade e à raça/cor, embora a predominância seja similar, o curso do IFF possui, percentualmente, mais estudantes jovens e brancos.

Esses indicativos, porém, não teriam efeitos significativos sobre o perfil de renda dos estudantes do curso em análise na comparação com os dados nacionais, considerando-se apenas o momento atual. Como é possível perceber na Figura 1, 73,6\% dos estudantes estão com renda familiar de até 3 salários mínimos (SM) neste período de pandemia, valores bem correspondentes aos dados do INEP (2017) referentes aos estudantes presenciais de licenciatura em Letras-Português no ano de aplicação do Exame: $72,8 \%$ também possuíam renda de até $3 \mathrm{SM}$, embora com percentuais detalhados invertidos (41,4\% com até 1,5 SM e 31,4\% entre 1,5 e 3 SM) em relação ao perfil dos estudantes de Letras do IFF.

Figura 1: Renda total familiar em salários mínimos durante a pandemia

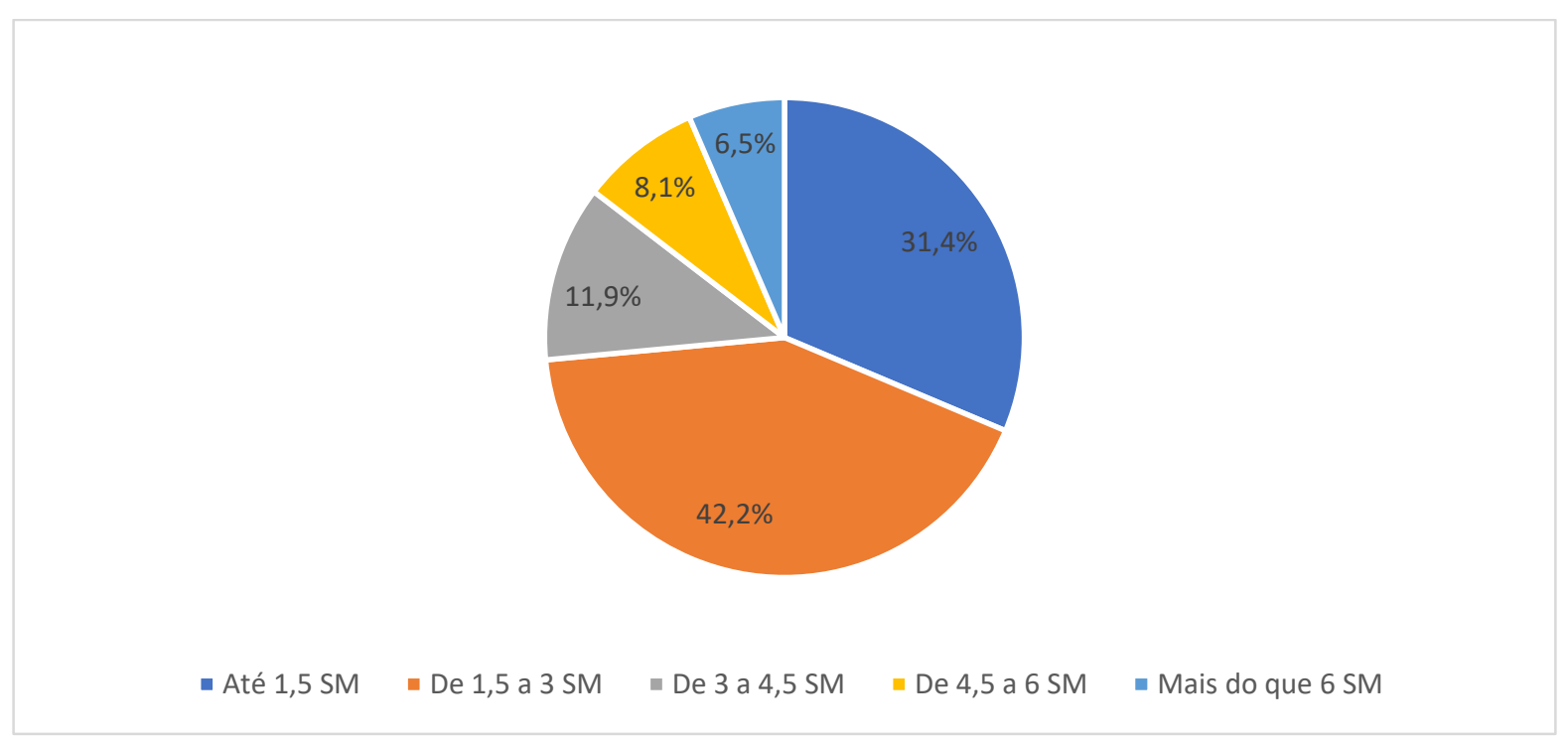

Fonte: Elaboração própria.

No entanto, uma comparação estanque dos dados de renda nacionais de 2017 com as informações atuais do IFF tende a esconder um processo de empobrecimento dos estudantes do curso em questão. Conforme dados produzidos por uma pesquisa de perfil realizada pelo colegiado da Licenciatura em Letras - Português e Literaturas do IFF em 2018 (RANGEL, SILVA e SILVA, 2019), a renda das famílias dos estudantes apresentava a seguinte configuração: $8,1 \%$ viviam com menos de 1 SM, 45,2\% viviam valores entre 1 e menos de 3 SM, 29,8\% viviam com valores entre 3 e menos 
que 5 SM e 17\% viviam com 5 SM ou mais. Colocando em comparação os dados recolhidos na presente pesquisa em período de pandemia com aqueles do levantamento de 2018, temos o seguinte:

Tabela 1: Comparativo entre a renda média das famílias dos estudantes da Licenciatura em Letras - Português e Literaturas do IFF entre 2018 e 2020

\begin{tabular}{ccc}
\hline & 2020 (pandemia) & 2018 \\
\hline Menos de 1 SM & $14,1 \%$ & $8,1 \%$ \\
De 1 a menos de 3 SM & $59,2 \%$ & $45,2 \%$ \\
De 3 a menos de 5 SM & $17,4 \%$ & $29,8 \%$ \\
5 ou mais SM & $9,2 \%$ & $17 \%$ \\
\hline
\end{tabular}

Fonte: Rangel, Silva e Silva (2019) e pesquisa (elaboração própria).

Como é possível perceber, ocorreu uma queda no nível de renda dos alunos, demonstrada no aumento percentual dos que vivem com renda de até $3 \mathrm{SM}$ e na diminuição dos que vivem com rendas acima de $3 \mathrm{SM}$, sinalizando um processo pauperização das famílias, com destaque para as que vivem com menos de $1 \mathrm{SM}$, agora correspondentes a 14\% do curso. Conforme salientam Netto e Braz (2010), as crises não interessam a nenhum dos sujeitos sociais dentro do capitalismo, sejam eles trabalhadores ou burgueses. Elas chegam a atingir, principalmente quando possuem as proporções da atual, segmentos do capital, em especial pequenas e médias empresas. Contudo, os "impactos atingem muito diferentemente as classes sociais; não há o mesmo custo para todos: os trabalhadores sempre pagam o preço mais alto" (NETO E BRAZ, 2010 , p. 163).

Esse cenário é ainda mais grave em países com um sistema de proteção social frágil como o brasileiro, no qual as políticas sociais carecem de financiamento, recebendo uma parcela insuficiente do fundo público para a manutenção dos padrões de atendimento necessários à garantia da dignidade humana, conforme preconiza a Constituição Federal de 1988. Nessa perspectiva, a política social torna-se dependente da política macroeconômica e da lógica do "permanente ajuste fiscal" do Estado brasileiro, enveredando, nas palavras de Behring e Boschetti (2010, p 184), "pelos caminhos da privatização para os que podem pagar, da focalização/seletividade e políticas pobres para os pobres, e da descentralização, vista como desconcentração e desresponsabilização do Estado, apesar das inovações de 1988".

Prova material disso, neste período de pandemia, deu-se na grande discussão travada em torno do pagamento do "auxílio emergencial" definido na Lei 13.982 de 2 de Abril de 2020. Enquanto o governo queria pagar apenas $\mathrm{R} \$ 200,00$ para autônomos de baixa renda, o Congresso 
Nacional acabou por aprovar um benefício de $\mathrm{R} \$ 600,00$ ou $\mathrm{R} \$ 1200,00$ (este no caso de mulheres solteiras e com filhos), por três meses (atualmente estendido, embora com redução de 50\% no valor). O benefício é pago para quem não tem emprego formal ativo e possuí renda inferior a um salário mínimo e meio per capita ou renda total familiar de até três salários.

A discussão e a demora na efetivação do pagamento desses benefícios são resultados de um processo de degradação das políticas sociais mais abrangentes e fundadas na ideia de trabalho formal, em constante queda no Brasil desde a aprovação da Reforma Trabalhista de 2017 - Lei no 13.467 de 13 de julho de 2017. Essa legislação, entre outros pontos, flexibilizou garantias como jornada de trabalho, férias, proteção contra insalubridade e permitiu a prevalência de acordos coletivos sobre a legislação trabalhista, facilitando demissões. O resultado, desde então, tem sido o aumento constante dos índices de informalidade, que, segundo o IBGE (2019), bateram recorde histórico em setembro de 2019, com 41,4\% da mão de obra ocupada em situação de informalidade, além de uma taxa de desemprego de $11,8 \%$.

Sem trabalho formal, milhares de famílias acabaram ficando sem os benefícios de proteção da previdência social, resultando em uma massa de pessoas que, impedidas ou limitadas em relação ao trabalho informal durante a pandemia, deixaram de ter a renda necessária ao seu sustento. Somado a isso, tem-se no Brasil um sistema de saúde que, apesar de definido como universal na Constituição de 1988, ainda apresenta abrangência e qualidade de atendimento insuficientes. Esse processo vem se agravando desde a aprovação da Emenda Constitucional no 95 de 15 de Dezembro que 2016, que limita o financiamento das políticas sociais pelo Estado (inclusive saúde e educação) pelos próximos vinte anos (a contar de 2017).

Sem acesso à previdência e sujeito a um atendimento inadequado no Sistema Único de Saúde, coube ao auxílio emergencial "dar conta" da desproteção social a que foram submetidos os $41,4 \%$ da população ocupada que estava sujeita a informalidade até o final de 2019. Esse cenário nacional se refletiu no curso de Letras - Português e Literaturas do IFF, fazendo com que, na pesquisa realizada com os alunos neste período de pandemia, fosse possível identificar que 44,2\% das famílias dos estudantes estão vivendo de algum benefício ou auxílio pago pelo Estado no momento. Em relação aos valores desses benefícios ou auxílios, tem-se o seguinte: 
Figura 2: Valor do benefício ou auxílio estatal em R\$

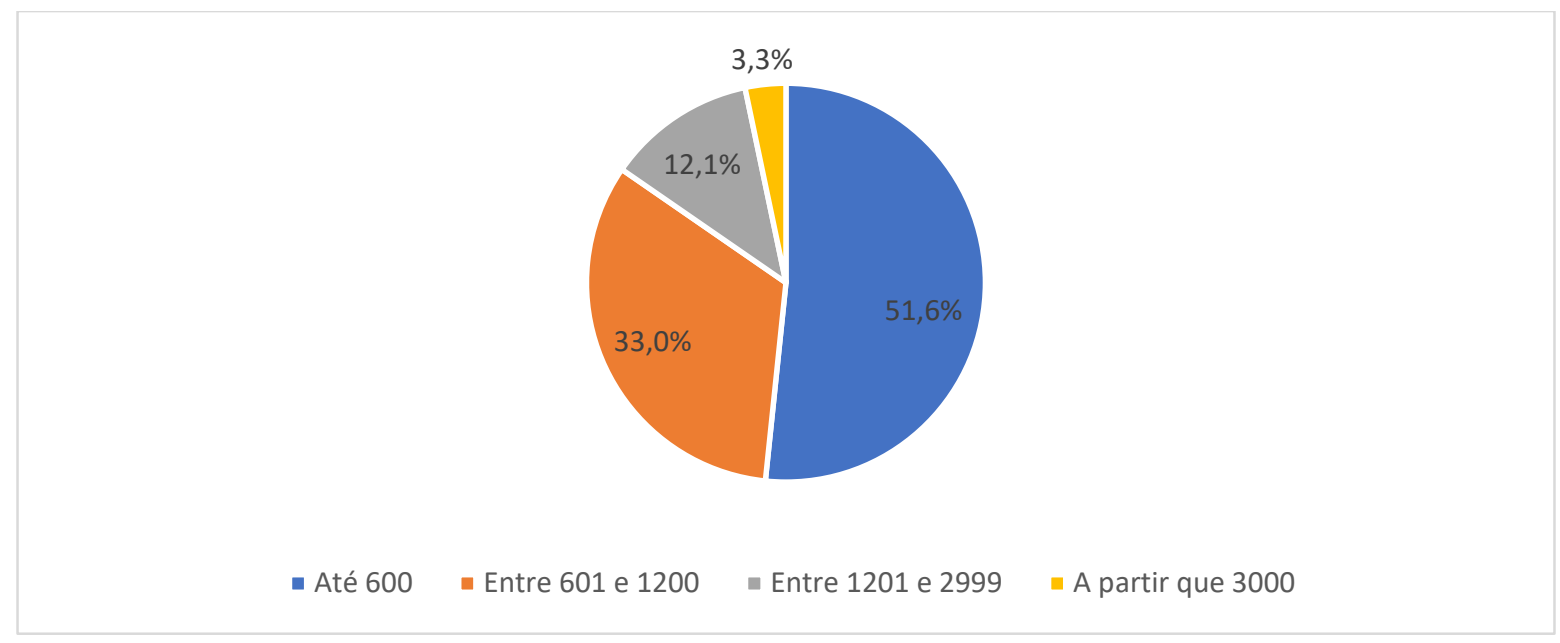

Fonte: Elaboração própria.

Pelos valores apresentados, é possível perceber que a maioria dos que estão dependendo de benefícios ou auxílios estatais recebem valores de até $\mathrm{R} \$ 1200,00$. No entanto, como também ficou definido na Lei 13.982 de 2 de Abril de 2020, que criou o auxílio emergencial, este benefício terá caráter temporário. Nessa conjuntura, outros dois fatores entram em questão, os quais dizem respeito ao número de membros dessas famílias e ao número de pessoas economicamente ativas ou com renda em cada uma delas, conforme as figuras 3 e 4.

Figura 3: Quantidade de pessoas que residem na mesma casa

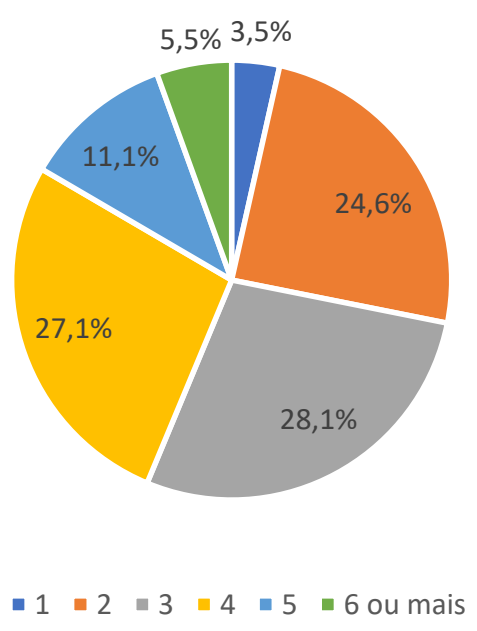


Figura 4: Quantidade de membros da família que possuem renda

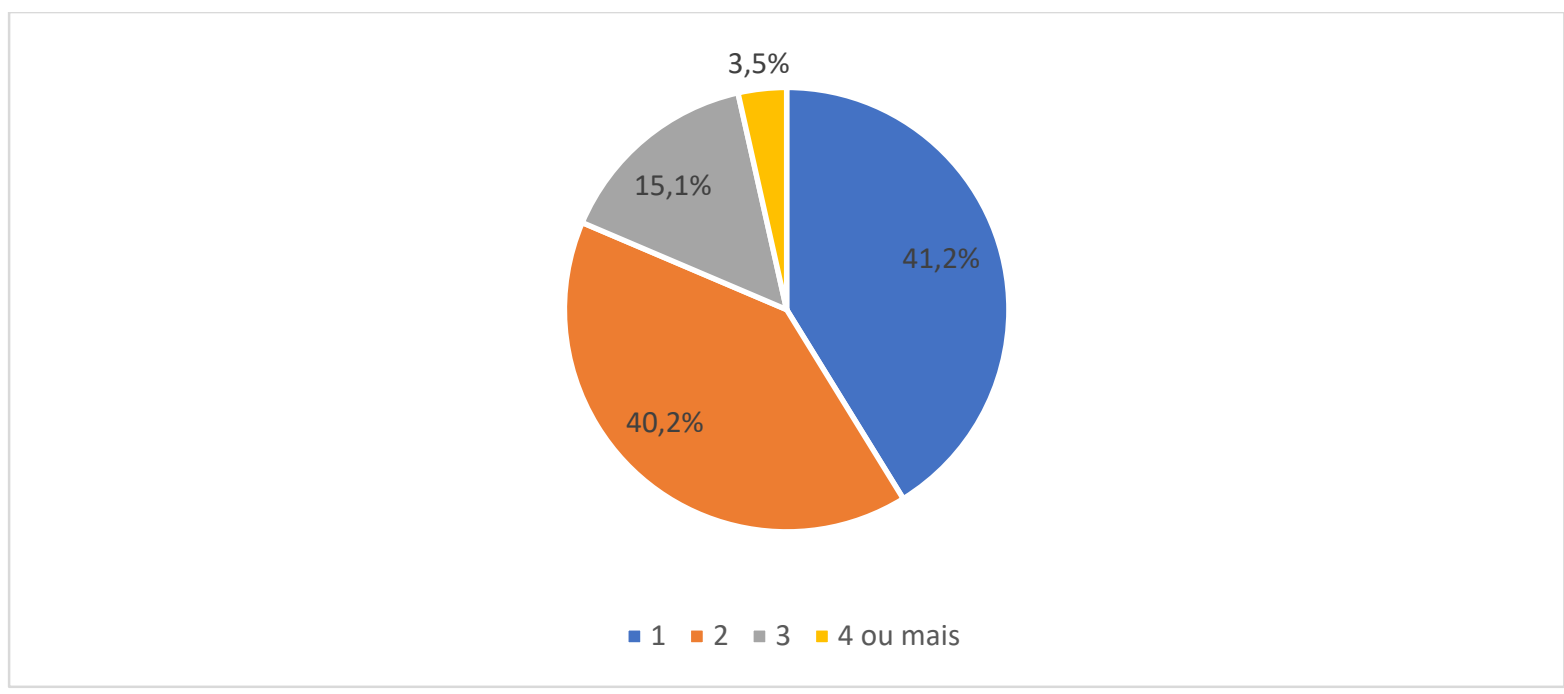

Fonte: Elaboração própria.

Como é possível verificar, apesar da maioria das famílias possuir uma composição que varia de 2 a 5 membros, 41,2\% delas possui apenas um provedor. Esses elementos, somados aos dados sobre informalidade e desproteção social já discutidos, evidenciam a fragilidade das condições de permanência desses estudantes no ensino superior. Se esse provedor adoece, morre ou fica impedido de exercer seu trabalho por algum motivo, como na atual situação sanitária, a reprodução material de toda família fica comprometida. Em muitos casos, como já demonstrou Zago (2006), os alunos são obrigados a dividir-se entre os estudos e o trabalho, prejudicando a sua experiência acadêmica - isso quando não são levados a abandonarem seus cursos.

É preciso lembrar que a ideia de permanência no ensino superior vem desenvolvida por autores como Zago (2006), Reis e Tenório (2009), Carmo e Carmo (2014) e Felippe (2015; 2016) associada a um sentido de resistência, de manter-se no curso apesar das dificuldades. Essas dificuldades podem ser de ordem simbólica, que envolvem questões como pertencimento ao ambiente universitário e aceitação pelo grupo, mas, quando se trata de alunos com o perfil dos licenciandos no Brasil, não seria possível ignorar a prevalência dos aspectos materiais, que dizem respeito às próprias condições de reprodução da vida, sem as quais, muitas vezes, estudar torna-se inviável. No caso do curso de Licenciatura em Letras-Português do IFF, a situação pode ser ilustrada pela renda per capita das famílias (já contabilizando os valores recebidos em benefícios e auxílios estatais). 
Figura 5: Renda per capita familiar

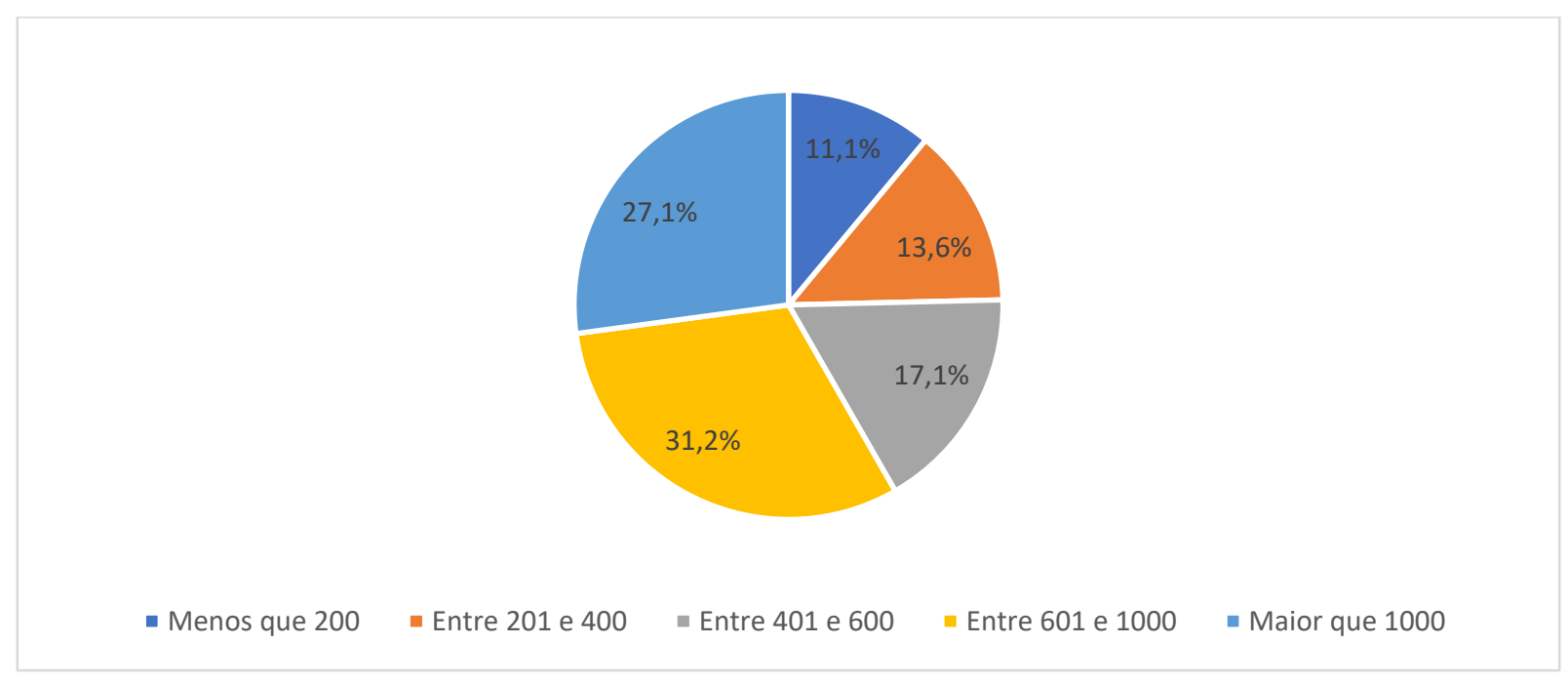

Fonte: Elaboração própria.

Chama atenção o fato de cerca de $73 \%$ das famílias estarem vivendo com menos de 1 SM per capita nesse período de pandemia, o que já os colocaria em perfil direto para as ações de assistência estudantil prevista pelo Decreto Federal no 7.234 de 2010, que estabelece o Plano Nacional de Assistência Estudantil (PNAES). No entanto, no momento da pesquisa, $90 \%$ dos alunos informaram não receber qualquer tipo de auxílio ou bolsa de assistência estudantil pela instituição.

Considerando tais elementos, os alunos foram indagados se estavam ou não com dificuldades para arcar gastos regulares básicos durante a pandemia. As respostas obtidas apontam que $66,8 \%$ não apresentavam dificuldades no momento, inclusive porque estavam recebendo o "auxílio emergencial" de caráter temporário, mas 33,2\% ainda tinham dificuldades para arcar com a manutenção básica da família. Perguntou-se, então, a este último grupo, quais seriam esses gastos - vide Figura 6. A soma dos percentuais a essa questão ultrapassa $100 \%$ em razão da possibilidade de se informar mais de uma opção. 
Figura 6: Gastos que os estudantes e suas famílias estão tendo dificuldade para custear

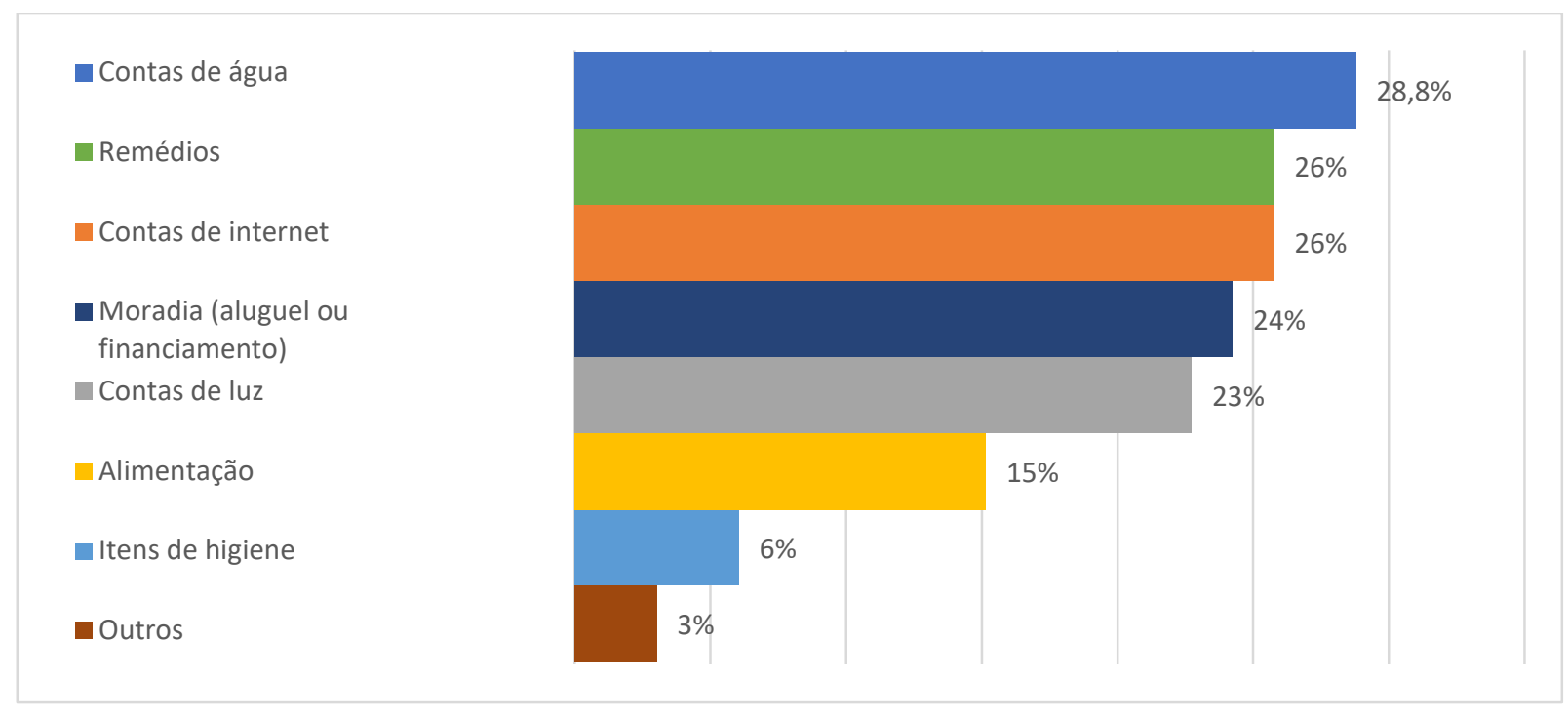

Fonte: Elaboração própria.

Essa parcela dos estudantes que relatou dificuldades para arcar com gastos regulares, em sua absoluta maioria, descreve necessidades fundamentais que poderiam ser interpretadas à luz da discussão travada por Pereira (2011) sobre os conceitos de necessidades básicas e mínimos sociais. Enquanto o primeiro "constitui o pré-requisito ou as condições prévias suficientes para o exercício da cidadania em sua acepção mais larga", o segundo refere-se a algo menor "em sua acepção mais ínfima, identificada com patamares de satisfação de necessidades que beiram a desproteção social" (PEREIRA, 2011, p. 26).

Nesse sentido, considera-se que o atendimento às demandas de alimentação, luz, água, moradia, transporte, higiene, saúde, acesso digital etc. são necessidades básicas que deveriam ser garantidas a todos os alunos, sem as quais o exercício do direito social à educação já está prejudicado. É preciso romper com a ideia de que o direito à educação é garantido apenas com a presença física ou, na conjuntura atual, virtual na aula, ignorando as desigualdades sociais e educacionais a que estão submetidos boa parte desses estudantes. Falar em permanência na educação é, portanto, falar em garantia do atendimento às necessidades básicas de reprodução dos estudantes e suas famílias, o que demanda uma rede de proteção ampla, envolvendo diversas políticas sociais.

No caso dos alunos em questão e no contexto atual de crise sanitária e social, com dificuldades para arcar com demandas como as que foram relatadas, retoma-se a pergunta inicial desse artigo: como seria possível pensar em estratégias de ensino que não ignorem esses fatores e 
promovam ainda mais desigualdade social e educacional? Um dos caminhos que tem sido amplamente discutido e até mesmo incentivado pelo Ministério da Educação é a adoção de aulas por meios digitais, aspecto já abordado. Fica, todavia, o questionamento: seria viável (em termos mentais, pedagógicos e materiais) para essa parcela significativa de alunos que está tendo dificuldades para comer, morar e pagar contas básicas ter uma rotina regular de aulas e compromissos acadêmicos? Caso a resposta seja negativa, a melhor alternativa, tratando-se de ensino superior, seria abrir mão de todas as atividades e aguardar uma solução definitiva como uma vacina?

Para realizar qualquer atividade por meios digitais, seria preciso saber se os estudantes possuem acesso aos dispositivos e recursos tecnológicos necessários ao acompanhamento das ações propostas. Buscando responder a essa questão, foram feitos os levantamentos cujos resultados estão descritos na Figura 7.

Figura 7: Acesso a dispositivos e recursos tecnológicos básicos

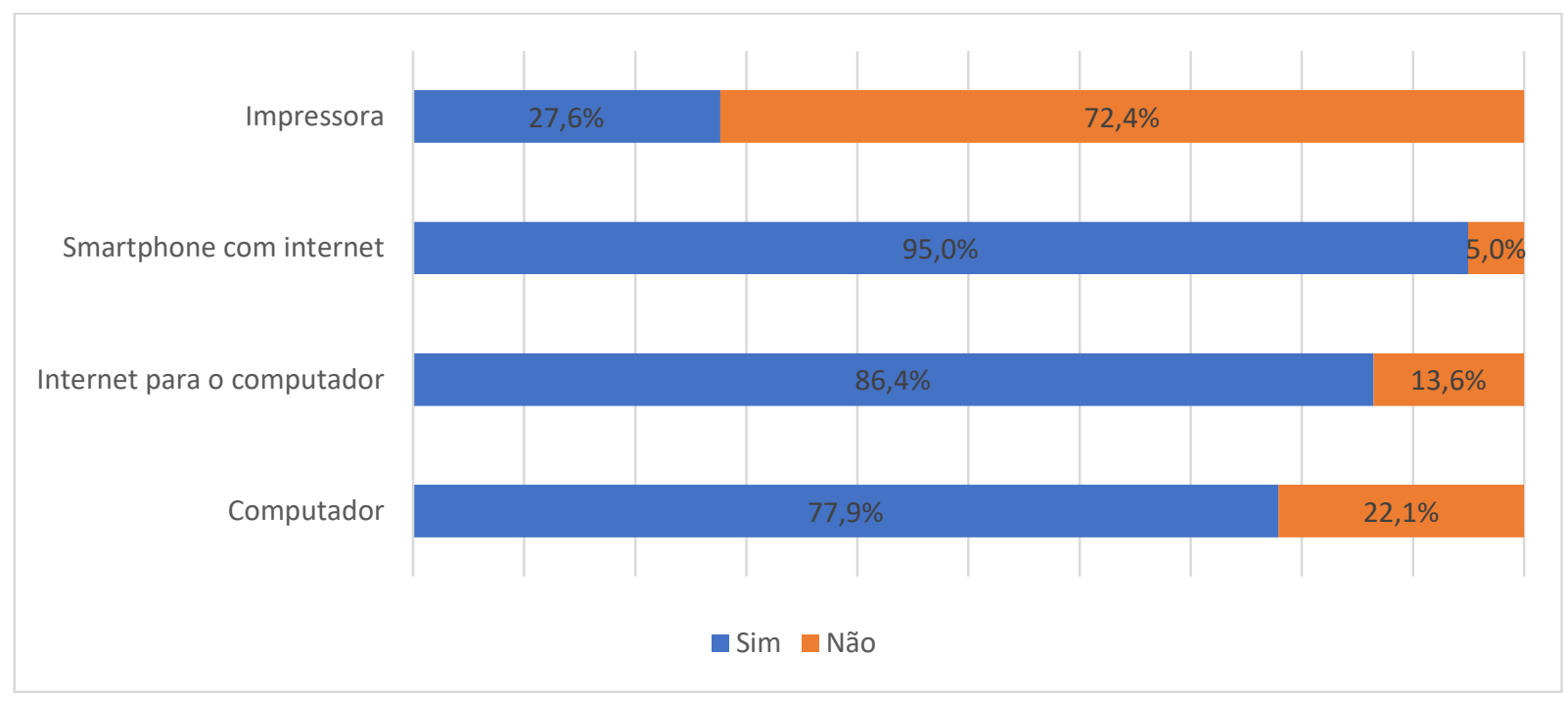

Fonte: Elaboração própria.

Embora a maioria absoluta tenha acesso à smartphone com internet, ainda existe um contingente de $5 \%$ (equivalente a 10 alunos entre os respondentes) que não tem acesso à rede mundial de computadores por esse dispositivo. Os dados em relação à internet banda larga e ao acesso a computador são mais comprometedores, chegando à indisponibilidade de $22,1 \%$ (cerca de 40 alunos) no caso do último. Como já foi descrito, isso refere-se apenas ao curso de Licenciatura em Letras - Português e Literaturas, mas o Instituto Federal Fluminense possui, apenas no campus 
Campos Centro, outros cinco cursos de licenciatura, além de mais de uma dezena de outros cursos de bacharelado, tecnologia e técnicos de nível médio, totalizando mais de cinco mil matriculados.

Inicialmente, a adoção de aulas regulares online deveria prever, ignorando todos os demais fatores materiais, pedagógicos e mentais já sinalizados, a provisão desses dispositivos e recursos para os que não têm acesso. Com a estrutura e os materiais disponíveis na instituição, talvez fosse possível o empréstimo de equipamentos e o custeamento do acesso digital via assistência estudantil (eixo previsto no PNAES). Entretanto, caberiam aqui duas novas perguntas: 1 - Seria possível fazer isso para um contingente similar a esse em todos os cursos? 2 - Recebido um benefício de assistência estudantil, dadas as necessidades básicas materiais de reprodução relatadas, seria prioritário para a realidade desse estudante investir tal recurso na aquisição de um pacote de internet?

Essas são perguntas que devem ser respondidas não apenas pela instituição em análise, mas por todas aquelas que estão formulando estratégias e mecanismos para adoção de aulas regulares por meios digitais, partindo sempre do conhecimento da realidade objetiva dos seus alunos. Talvez alguma solução possa ser encontrada também na adoção de estratégias diversas, que, no caso do curso de licenciatura pesquisado, podem ser agrupadas nos seguintes eixos:

Figura 8: Adequação de recursos remotos de ensino à realidade dos estudantes

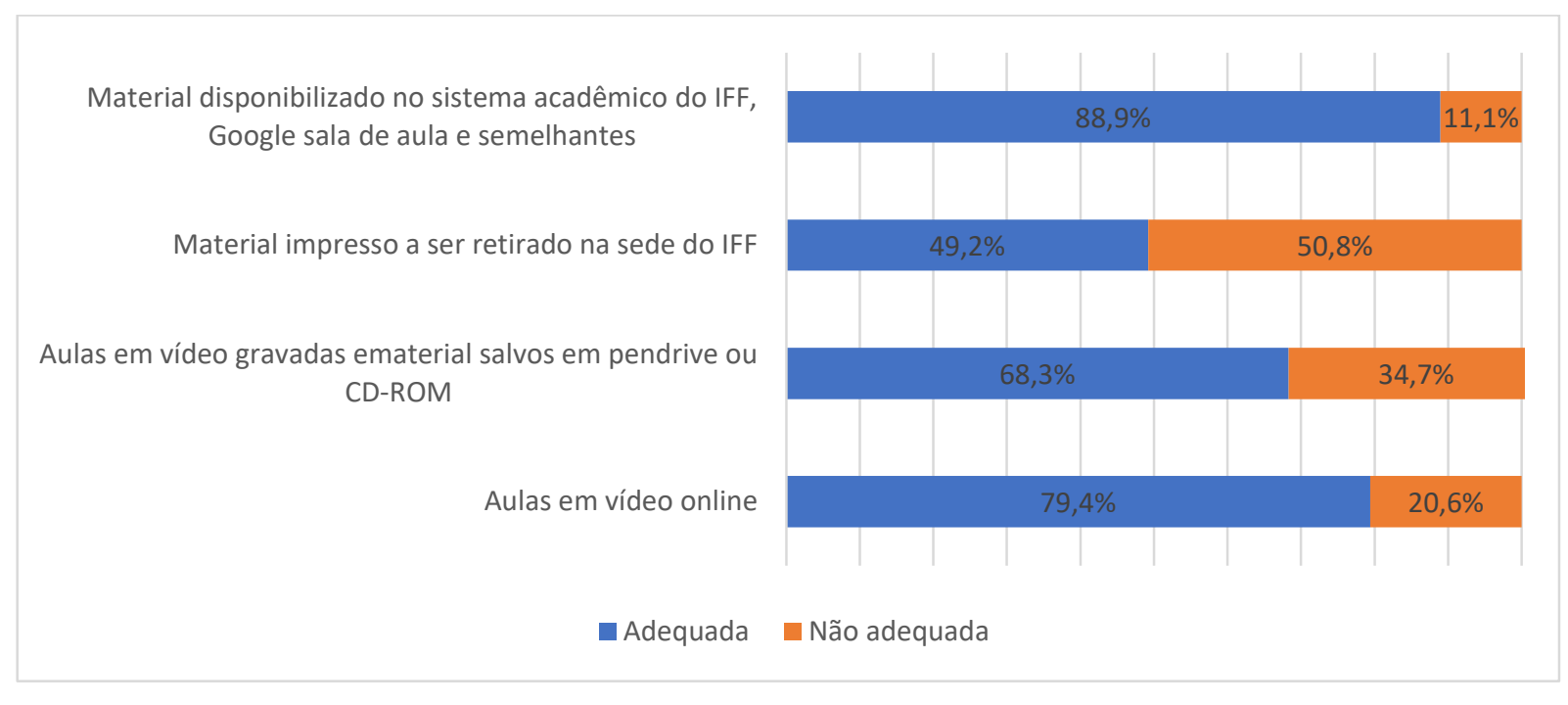

Fonte: Elaboração própria.

Nenhuma das estratégias, porém, atinge a totalidade dos estudantes, até porque $26,6 \%$ residem em outros municípios e 11,1\% em área rural de Campos dos Goytacazes - RJ, o que dificultaria a retirada de material ou mesmo o acesso ao sinal de internet. Deixar os alunos sem qualquer atividade também não parece ser uma decisão acertada, no caso específico em discussão, 
uma vez que mais de $90 \%$ dos alunos relataram interesse em realizar atividades vinculadas ao curso mesmo durante a pandemia e 96\% informaram que não cogitam abandoná-lo após a crise sanitária, o que demonstra um baixo índice de desengajamento em relação à Licenciatura em Letras Português e Literaturas até o momento.

\section{CONSIDERAÇÕES FINAIS}

No caso específico do curso em análise, em um primeiro momento, uma alternativa foi a utilização de dispositivos e recursos de tecnologia da informação e da comunicação não para substituir as aulas regulares, mas para promover momentos de reflexão e discussão sobre o momento atual e seus impactos na própria educação escolar, já que se trata de um curso de formação de professores. Além disso, os próprios estudantes realizaram a proposição de temáticas transversais ao curso ou de aprofundamento nos estudos sobre a língua, a literatura e a educação

Outra iniciativa foi, como já relatado, a identificação dos alunos que estão em situação de maior dificuldade para arcar com seus gastos regulares. Esses estudantes foram contactados pela coordenação do curso e encaminhados à equipe de assistência estudantil do campus, que acabou por atender alguns deles por meio de bolsas institucionais emergenciais.

Tais ações e todas as outras que possam vir a ser pensadas pelas instituições a partir do conhecimento da realidade dos seus estudantes devem ter como foco central a busca pela permanência desses alunos na educação. Essa permanência, porém, não deve se resumir à manutenção da matrícula ou da presença física/virtual nas aulas, mas deve basear-se na garantia das condições materiais, mentais e simbólicas efetivas de aprendizado e de vivência acadêmica nos cursos. Esse deve ser o norte em períodos de aulas regulares e, ainda mais, em fases críticas como a que vivemos. Para finalizar, resgata-se a lucidez e o discernimento da professora Ângela Dalben, que em entrevista a uma revista de grande circulação em maio 2020 declarou que este não será um ano perdido "se soubermos entender e interpretar o que está acontecendo" (DALBEN, 2020).

\section{REFERÊNCIAS}

ARANHA, Antônia Vitória Soares; SOUZA, João Valdir Alves de. As licenciaturas na atualidade: nova crise? Educar em Revista. Curitiba: n. 50, p. 69-86, 2013. 
BEHRING, Elaine Rossetti.; BOSCHETTI, Ivanete. Política social: fundamentos e história. São Paulo: Cortez, 2010.

BRASIL. Lei 11.892 de 29 de dezembro de 2008: Institui a Rede Federal de Educação Profissional, Científica e Tecnológica, cria os Institutos Federais de Educação, Ciência e Tecnologia, e dá outras providências. Disponível em: <http://www.planalto.gov.br/ccivil_03/_ato20072010/2008/lei/l11892.htm>. Acesso em 06 de junho de 2020.

BRASIL. Decreto no 7.234 de 19 de julho de 2010: Dispõe sobre o Programa Nacional de Assistência Estudantil (PNAES). Disponível em: <http://www.planalto.gov.br/ccivil_03/_Ato20072010/2010/Decreto/D7234.htm>. Acesso em 06 de junho de 2020.

BRASIL. Lei no 13.005 de 25 de junho de 2014: Aprova o Plano Nacional de Educação e dá outras providências. Disponível em: <http://www.planalto.gov.br/ccivil_03/_ato20112014/2014/lei/l13005.htm>. Acesso em 06 de junho de 2020.

BRASIL. Emenda Constitucional no 95 de 15 de dezembro de 2016:

Altera o Ato das Disposições Constitucionais Transitórias, para instituir o Novo Regime Fiscal, e dá outras providências. Disponível em:

<http://www.planalto.gov.br/ccivil_03/constituicao/emendas/emc/emc95.htm>. Acesso em 06 de junho de 2020.

BRASIL. Lei no 13.467 de 13 de julho de 2017: Altera a Consolidação das Leis do Trabalho (CLT), aprovada pelo Decreto-Lei $n=5.452$, de 1 을 de maio de 1943, e as Leis $\mathrm{n} \underline{\mathbf{0}} 6.019$, de 3 de janeiro de 1974, 8.036, de 11 de maio de 1990, e 8.212, de 24 de julho de 1991, a fim de adequar a legislação às novas relações de trabalho. Disponível em: <http://www.planalto.gov.br/ccivil_03/_ato20152018/2017/lei/l13467.htm>. Acesso em 06 de junho de 2020.

BRASIL. Lei no 13.982 de 2 de abril de 2020: altera a Lei $n$ o 8.742, de 7 de dezembro de 1993, para dispor sobre parâmetros adicionais de caracterização da situação de vulnerabilidade social para fins de elegibilidade ao benefício de prestação continuada (BPC), e estabelece medidas excepcionais de proteção social a serem adotadas durante o período de enfrentamento da emergência de saúde pública de importância internacional decorrente do coronavírus (Covid-19) responsável pelo surto de 2019, a que se refere a Lei № 13.979, de 6 de fevereiro de 2020. Disponível em: < http://www.planalto.gov.br/ccivil_03/_ato2019-2022/2020/lei//13982.htm>. Acesso em 06 de junho de 2020.

BRASIL. Ministério da Educação. Portaria no 343 de 17 de março de 2020: Dispõe sobre a substituição das aulas presenciais por aulas em meios digitais enquanto durar a situação de pandemia do Novo Coronavírus - COVID-19. Disponível em:

<https://abmes.org.br/arquivos/legislacoes/Portaria-mec-343-2020-03-17.pdf>. Acesso em 26 de junho de 2020.

BRASIL. Ministério da Educação. Portaria no 473 de 12 de maio de 2020: Prorroga o prazo previsto no $\S 1$ 을 do art. 10 da Portaria no 343, de 17 de março de 2020. Disponível em:

<https://abmes.org.br/arquivos/legislacoes/Portaria-mec-473-2020-05-12.pdf>. Acesso em 26 de junho de 2020. 
BRASIL. Ministério da Educação. Portaria no 544 de 16 de junho de 2020: Dispõe sobre a substituição das aulas presenciais por aulas em meios digitais, enquanto durar a situação de pandemia do novo coronavírus - Covid-19, e revoga as Portarias MEC n ㄴ 343, de 17 de março de 2020, no 345, de 19 de março de 2020, e no 473, de 12 de maio de 2020. Disponível em: $<$ https://abmes.org.br/arquivos/legislacoes/Portaria-mec-544-2020-06-16.pdf>. Acesso em 26 de junho de 2020.

CARMO, Gerson Tavares do.; CARMO, Cíntia Tavares do. A permanência escolar na Educação de Jovens e Adultos: propostas de categorização discursiva a partir das pesquisas de 1998 a 2012 no Brasil. Arquivos Analíticos de Políticas Educativas, v. 22, n. 63, 2014.

DALBEN, Ângela Imaculada Loureiro de Freitas. Entrevista, Rio de Janeiro (Rio de Janeiro). 19 de maio de 2020. Disponível em: <https://epoca.globo.com/nao-sera-um-ano-perdido-se-soubermosinterpretar-que-esta-acontecendo-diz-secretaria-de-educacao-de-bh-24411082>. Acesso em 06 de junho de 2020.

FELIPPE, Jonis Manhães Sales. Assistência estudantil no Instituto Federal Fluminense: possibilidades e limites para a permanência escolar e conclusão do curso dos estudantes. Textos e Contextos, Porto Alegre, v. 14, n. 1, p. 145-155, 2015.

FELIPPE, Jonis Manhães Sales. Crescimento da oferta e a permanência dos estudantes: o debate sobre a assistência estudantil e os desafios da educação superior pública no Brasil. Revista Cocar, Belém, v. 10, n. 20, p. 113-120, 2016.

GATTI, Bernadete Angelina. Formação de professores no Brasil: características e problemas. Educação \& Sociedade, Campinas, v. 31, n. 113, p. 1355-1379, 2010.

INSTITUTO BRASILEIRO DE GEOGRAFIA E ESTATÍSTICA. Desemprego cai para 11,8\% com informalidade atingindo maior nível da série histórica, 2019. Disponível em:

<https://censo2020.ibge.gov.br/2012-agencia-de-noticias/noticias/25534-desemprego-cai-para11-8-com-informalidade-atingindo-maior-nivel-da-serie-historica.html>. Acesso em 06 de junho de 2020.

INSTITUTO FEDERAL FLUMINENSE. Projeto Pedagógico do curso superior de Licenciatura em Letras - Português e Literaturas do Instituto Federal Fluminense campus Campos Centro, 2019. Disponível em: <http://cdd.iff.edu.br/documentos/resolucoes/2019/resolucao-32>. Acesso em 06 de junho de 2020.

INSTITUTO NACIONAL DE ESTUDOS E PESQUISAS EDUCACIONAIS ANÍSIO TEIXEIRA. Relatório síntese da área de Letras-Português (bacharelado e licenciatura), 2017. Disponível em: <http://download.inep.gov.br/educacao_superior/enade/relatorio_sintese/2017/LetrasPortugues.pdf >. Acesso em 06 de junho de 2020.

LAHIRE, Bernard. Sucesso escolar nos meios populares: as razões do improvável. São Paulo: Editora Ática, 2008. 
MELLO, Jorge da Silva. Desigualdades sociais e acesso seletivo ao ensino superior no Brasil no período1994-2001. Revista Iberoamericana sobre Calidad, Eficacia y Educación. V. 5, n. 2, p. 6983, 2007.

NETTO, José Paulo; BRAZ, Marcelo. Economia política: uma introdução crítica. São Paulo: Cortez, 2010.

PEREIRA, Potyara Amazoneida Pereira. Necessidades humanas: subsídios à crítica dos mínimos sociais. São Paulo: Cortez, 2011.

RANGEL, Angellyne Moço Rangel; SILVA, Camille Auatt da; Marília Siqueira da; SILVA. Relatório de pesquisa: indicadores sobre permanência estudantil no curso de Licenciatura em Letras. Campos dos Goytacazes: IFF, 2019.

REIS, Dyane Brito; TENÓRIO, Robinson Moreira. Cotas e estratégias de permanência no ensino superior. In: TENÓRIO, Robinson Moreira.; VIEIRA, Marcos Antônio. (Orgs). Avaliação e Sociedade: a negociação como caminho. Salvador: EDUFBA, 2009.

ZAGO, Nadir. Do acesso à permanência no ensino superior: percursos de estudantes universitários de camadas populares. Revista Brasileira de Educação. V. 11, n.32, maio/ago 2006.

\section{SOBRE O AUTOR}

\section{Jonis Manhães Sales Felippe}

Doutor em Políticas Sociais pela Universidade Estadual do Norte Fluminense Darcy Ribeiro (UENF); Professor da área de Educação no Instituto Federal Fluminense - campus Campos Centro. Pesquisador dos Núcleo de Estudos Avançados em Educação (NESAE) e do Núcleo de Estudos e Pesquisas em Políticas Educacionais e Formação Docente (Pólis).

E-mail: jonisfelippe@gmail.com

ORCID: https://orcid.org/0000-0002-1175-7637

Recebido em: 01/07/2020

Aprovado em: 20/10/2020

Publicado em: 04/11/2020 